\title{
Riesgos tecnológicos, conflictos sociales y políticas ambientales. Del estudio de las percepciones a la implicación pública
}

\author{
Ana Prades \\ Centro de Investigaciones Energéticas, Medioambientales y Tecnológicas. Centro de \\ Investigación Socio-Técnica (CIEMAT-CISOT) \\ ana.prades@ciemat.es

\section{Josep Espluga Trenc} \\ Universitat Autònoma de Barcelona. Departament de Sociologia \\ joseplluis.espluga@uab.cat

\section{Tom Horlick-Jones} \\ University of Cardiff. School of Social Sciences
}

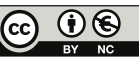

Recibido: 25-05-2015

Aceptado: 07-07-2015

\section{Resumen}

La gestión de los riesgos tecnológicos y ambientales, junto con la promoción del desarrollo sostenible, ha constituido un pilar esencial de las políticas públicas de las últimas décadas. Una buena parte de estas políticas ha pretendido influir en la opinión pública, fomentando comportamientos preventivos y/o evitando aquellos que no resultan sostenibles. Sin embargo, la ciudadanía no suele seguir estas recomendaciones sin más, sino que despliega un amplio rango de acciones que van desde la mera indiferencia hasta el rechazo o la protesta, lo que, a su vez, puede traducirse en una mayor degradación ambiental o en una excesiva exposición al riesgo por parte de la población. Este desajuste entre los objetivos de las políticas ambientales y los comportamientos de la ciudadanía constituye un aspecto crítico, tanto para la gobernanza del riesgo como para la legitimidad democrática. El presente artículo muestra cómo la investigación social ha intentado comprender y resolver estos retos. Mediante una revisión bibliográfica, se analiza el origen y la evolución de los estudios sobre percepción y comunicación social del riesgo, desde las aproximaciones más tecnocráticas de los inicios hasta las más participativas de los últimos tiempos, destacando sus fortalezas y debilidades respectivas. Finalmente, en un intento de ilustrar los enfoques actuales más innovadores, se introduce el método STAVE como un ejemplo de interconexión (mediante procedimientos de brokerage) de la esfera de la elaboración de políticas ambientales con la esfera de la vida cotidiana de la ciudadanía.

Palabras clave: riesgo ambiental; percepción del riesgo; comunicación del riesgo; gobernanza del riesgo; dimensiones sociales del riesgo; política ambiental; sostenibilidad; implicación ciudadana. 
Abstract. Technological risks, social conflicts and environmental policies: From the study of social perceptions to public engagement

The governance of environmental and technological risks, together with the promotion of sustainable development, has been a key pillar for public policy in recent decades. Such policies usually aim to influence public attitudes and citizen's behaviour in order to promote risk-preventive behaviours, and to prevent non-sustainable ones. Lay citizens, however, do not always simply follow such policy measures, they rather display a variety of actions, ranging from apathy or indifference to public opposition and rejection, further contributing to environmental degradation or to excessive risk exposure. Thus, there seems to be a clear mismatch between sustainable policy goals and the related daily behaviours of citizens, which is, indeed, a fundamental and critical issue for both risk governance and democratic legitimacy. This paper presents an overview of the social research on risk and its efforts for understanding, and contributing to solve, such challenges. Through a literature review, the origins and evolution of risk perception and risk communication research, from the more technocratic approaches of the $70 \mathrm{~s}$ up to more participative and recent approaches, highlighting strengths and weakness, are introduced and analysed. Finally, to illustrate the more recent and innovative approaches, we introduce the STAVE method as an example of interconnection (through brokerage proceedings) between the environmental policy-making sphere and the everyday sphere of citizens, combining elements of research and engagement to uncover daily experiences related to sustainable practices.

Keywords: environmental risk; risk perception; risk communication; risk governance; social dimensions of risk; environmental policy; policy making sustainability; citizen engagement.

\section{Sumario}

Introducción La evolución de la comunicación

El concepto de riesgo ambiental del riesgo y sus dimensiones sociales

Los orígenes de la investigación en percepción del riesgo y el debate sobre el riesgo aceptable

La percepción del riesgo desde el paradigma psicométrico Hacia la gobernanza del riesgo y la implicación ciudadana en las políticas ambientales STAVE: una propuesta de implicación ciudadana en las políticas ambientales

La percepción del riesgo desde la teoría cultural

La percepción del riesgo desde A modo de conclusión Agradecimientos Referencias bibliográficas perspectivas reflexivas e interpretativas

\section{Introducción}

El modelo de desarrollo de la sociedad capitalista industrial ha generado un creciente número de riesgos tecnológicos y organizativos cuyos impactos han deteriorado considerablemente el medio ambiente, agotando materias primas, recursos energéticos y agua potable; disminuyendo la biodiversi- 
dad; alterando los ciclos climáticos; contaminando la atmósfera, los cursos acuáticos y el suelo; provocando crisis alimentarias; etc. (Brundtland, 1989; EEA, 2013; Riechmann et al., 2012). Desde hace décadas, las instituciones públicas intentan elaborar políticas para afrontar y prevenir dichos riesgos, así como para promover un desarrollo más sostenible en términos ambientales, económicos y sociales. Estas políticas han esperimentado una evolución visible desde las acciones meramente reactivas de mediados del siglo $\mathrm{xx}$, pasando por las políticas preventivas de la década de 1970, cuando se identificaron numerosos factores de riesgo tecnológicos, y por las políticas precautorias de inicios del siglo XXI, encaminadas a restringir determinadas actividades o tecnologías en condiciones de incertidumbre respecto a sus posibles daños ambientales o a la salud.

Muchas de estas políticas ambientales pretenden incidir en las actitudes y en los comportamientos de la población, bien para que los ciudadanos aprendan a protegerse de los riesgos (o adaptarse a ellos) o bien para que eviten comportamientos poco sostenibles con el entorno (o mitiguen sus impactos). Sin embargo, las respuestas de los ciudadanos ante los riesgos tecnológicos y ambientales no siempre coinciden con lo que aquellas políticas públicas prevén o esperan. Unas veces, el público responde de manera conflictiva, planteando protestas abiertas y colectivas, mientras que, otras veces, parece ignorar las prescripciones de las políticas, con lo cual contribuyen a promover el deterioro ambiental o asumen unos riesgos mayores de los esperados. Desde el punto de vista de los decisores políticos, se diría que, en ocasiones, la población tiende a sobreestimar los riesgos (cuando protesta activamente), mientras que, en otras, tiende a minusvalorarlos (cuando ignora las medidas propuestas). En ambos casos, existe un claro problema de inadecuación entre lo que las políticas públicas pretenden y lo que los ciudadanos deciden hacer, lo que supone sin duda una cuestión relevante a la hora de afrontar los riesgos tecnológicos y ambientales (lo cual deviene una tarea cada vez más urgente), así como un cuestionamiento de la legitimidad de las decisiones tomadas por dichas instituciones y, por tanto, una erosión de la democracia.

Es a partir de las décadas de 1960 y 1970 cuando la acumulación de impactos tecnológicos empieza a generar una preocupación visible entre las poblaciones expuestas (Lemkow, 1984, 2002; Dobson, 1997). Se podría decir, de acuerdo con Beck (1992), que, al conflicto social e histórico por la distribución de recursos, se superpone el conflicto por la distribución de riesgos. Mientras que, en el pasado, la población expuesta a los riesgos tecnológicos y ambientales era, básicamente, la que habitaba en los alrededores de fábricas o barrios degradados, así como en lugares expuestos a riesgos naturales (inundaciones, terremotos, etc.), a partir de la década de 1960, cada vez hay más evidencias de que los impactos tecnológicos son ubicuos y afectan a la mayoría de la población, bien de manera directa (daños a la salud por contaminación de aguas, alimentos, aire, etc.), bien de manera indirecta (en forma de alteraciones ecosistémicas o de fenómenos globales como el cambio climático, etc.), e incluso para las generaciones venideras. 
También a partir de esa época se registran y aparecen en los medios de comunicación cada vez más accidentes e incidentes: nucleares, naufragios de petroleros, fugas químicas, destrucción de ecosistemas ante el avance de la urbanización, crisis energéticas, alarmas alimentarias, etc. Estos eventos motivan crecientes reacciones ciudadanas y plantean nuevos retos a las instituciones encargadas de garantizar niveles mínimos de seguridad y velar por la sostenibilidad ambiental. Pero, curiosamente, al mismo tiempo, también se dan numerosas situaciones de claros riesgos para la salud y el medio ambiente, en las que las personas expuestas parecen adoptar comportamientos poco preventivos, vulnerando las prescripciones de las instituciones encargadas de regularlos y aumentando su exposición al riesgo (en casos de población expuesta a riesgos laborales, residentes de zonas industriales, etc.; ver, por ejemplo: Espluga, 2004b, 2006; Espluga et al., 2009, 2014). A su vez, las políticas encaminadas a alcanzar una mayor sostenibilidad suelen requerir cambios en los hábitos y en los estilos de vida de la población dirigidos a minimizar su impacto en el entorno (ahorrando energía y agua, seleccionando los residuos domésticos, adquiriendo máquinas más eficientes, etc.). Tampoco en este contexto suele ser fácil que las medidas propuestas se adecúen a las actitudes y a las decisiones de los ciudadanos, lo que complica la consecución de los objetivos políticos respecto al medio ambiente.

Para completar el escenario, a partir del último tercio del siglo xx, muchos de los riesgos ambientales y tecnológicos presentan amplios grados de incertidumbre científica en cuanto a la caracterización de sus efectos (al menos de momento, lo que dificulta su diagnosis). Estos efectos, además, desbordan con frecuencia las fronteras político-administrativas de las instituciones clásicas (lo que dificulta su gestión) y, a menudo, suelen tener impactos irreversibles (o solo reversibles a muy largo plazo, lo que dificulta la atribución de responsabilidades y el establecimiento de mecanismos de seguros). Todo ello desafía el funcionamiento de las instituciones encargadas de la toma de decisiones (gobiernos de diferentes niveles, ministerios, agencias estatales, empresas, etc.), generando un clima de desconfianza que, a su vez, dificulta la eficacia de las medidas políticas para gestionar los riesgos, cuyos gestores pierden credibilidad en un círculo vicioso difícil de resolver.

Por ello, en el momento histórico en el que nos encontramos, con un modelo de desarrollo hegemónico basado en la innovación tecnológica permanente para un ciclo de producción y consumo de masas, con unos impactos ambientales locales y globales crecientes, las preocupaciones ambientales y las protestas contra los riesgos tecnológicos constituyen uno de los retos políticos contemporáneos clave. ¿Cómo gestionar unos riesgos tecnológicos y ambientales de los que todavía no se dispone de suficientes datos o evidencias empíricas, pero sobre los que hay que tomar decisiones inmediatas (permitirlos, prohibirlos, regularlos, etc.), como advertían Funtowicz y Ravetz (1990)? ¿Cómo implantar unas políticas ambientales y de sostenibilidad ecológica que se perciban como legítimas y necesarias por parte de la población que se va a ver afectada por ellas? ¿Cómo elaborar políticas ambientales y de sostenibili- 
dad que integren las distintas sensibilidades y los puntos de vista de diferentes sectores sociales, tanto expertos como legos, potencialmente afectados por aquellos riesgos?

Las ciencias sociales han intentado dar respuesta a estos grandes retos mediante dos subdisciplinas que acumulan ya casi medio siglo de desarrollo académico y práctico: los estudios sobre percepción social del riesgo y los estudios sobre comunicación del riesgo. En ambos casos, históricamente, encontramos una secuencia de diferentes paradigmas interpretativos sobre el riesgo y su gestión, la mayoría de carácter excesivamente reduccionista, hasta llegar a la situación actual, en la que toman cuerpo propuestas más complejas e integradoras.

El presente texto pretende describir esta evolución señalando aportaciones y limitaciones, así como valorar las tendencias actuales, finalizando con una breve descripción de una metodología de implicación ciudadana para la elaboración de políticas ambientales (la aproximación STAVE, desarrollada por los autores del texto en el marco del proyecto europeo PACHELBEL) ${ }^{1}$.

\section{El concepto de riesgo ambiental y sus dimensiones sociales}

De manera sintética, un riesgo es la posibilidad de que, en un futuro determinado, suceda algo negativo, básicamente un daño o una pérdida, a causa de un peligro (o un factor de riesgo). De acuerdo con la tradición técnica de los análisis de riesgo, dicha posibilidad se puede estimar mediante un cálculo de probabilidades a lo largo de un periodo de tiempo, y también es posible estimar la magnitud de los daños o de las pérdidas que se pueden producir en una situación dada. Esta información constituye una base fundamental para la toma de decisiones, por lo que el riesgo se convierte en un concepto normativo con importantes repercusiones sociales, económicas, políticas, etc. Si, en una situación concreta, los cálculos de riesgo muestran que la probabilidad de ocurrencia de un daño y/o su magnitud pueden ser elevadas, entonces hay que actuar para evitarlo. Por ello, el concepto de riesgo tiene un alto componente político, pues no solo sirve para describir técnicamente una situación dada, sino que también orienta la toma de decisiones, exige pasar a la acción e intervenir sobre la realidad.

Además, el concepto de riesgo remite al futuro, puesto que habla de algo que todavía no ha pasado pero puede llegar a suceder. Su definición siempre

1. El proyecto PACHELBEL (Policy Addressing Climate Change and Learning about Consumer Behaviour and Everyday Life) se realizó entre 2010 y 2012 y fue financiado por la Comisión Europea en el marco del FP7. Participaron diez instituciones de seis países europeos: Alemania (Dialogik Institute), España (CIEMAT-CISOT, Amphos-21 y UAB), Francia (Symlog Institute), Reino Unido (University of Cardiff, University of Brunel, LSE), Rumanía (Meda-Research) y Suecia (FHS). El proyecto se centró en analizar la toma de decisiones a la hora de planificar políticas ambientales (principalmente relacionadas con el cambio climático) dirigidas a modificar comportamientos cotidianos, con la finalidad de desarrollar una metodología de implicación ciudadana útil para mejorar la elaboración de dichas políticas. Se puede encontrar más información en la web del proyecto: www.pachelbel.eu. 
está relativamente abierta, especialmente cuando no se dispone de suficiente evidencia para efectuar las estimaciones (por falta de registros históricos, por ejemplo), cuando se desconocen sus posibles efectos o cuando se dan discrepancias científicas sobre las metodologías más pertinentes para realizar estimaciones y cálculos. En estos casos de elevada incertidumbre, el concepto de riesgo se convierte en un verdadero campo de batalla entre diferentes actores (promotores o beneficiarios del riesgo, población afectada, organismos reguladores, etc.) que pugnan por imponer una definición del mismo. Y cada definición puede comportar un curso de acción distinto.

No todos los riesgos tecnológicos y/o ambientales generan tantas discrepancias, puesto que los hay bien conocidos, con suficientes evidencias sobre sus efectos adversos, y suficiente consenso en su definición entre los diversos actores implicados. Pero hay riesgos cuyas probabilidades y magnitudes no son fáciles de estudiar y la mera apelación a la opinión de los expertos no suele ser concluyente para poder tomar las mejores decisiones, unas decisiones que pueden afectar a la salud de la población o a la calidad ambiental de su territorio. Tomar decisiones en condiciones de incertidumbre requiere algo más que el asesoramiento experto, puesto que la ciencia no está en condiciones de cerrar controversias (al menos de momento, aunque puede que, con el tiempo, la investigación permita ir reduciendo aquella incertidumbre y ofrecer una base sólida para decidir sobre el riesgo).

Pero la toma de decisiones no solo se ve cuestionada en casos de incertidumbre respecto a los cálculos probabilísticos del riesgo, pues las discrepancias entre los actores también pueden (y suelen) aparecer al valorar las posibles consecuencias, los posibles daños o pérdidas. Los cálculos expertos suelen presuponer que los daños o pérdidas son básicamente de salud (humana) o ambientales (desequilibrios ecosistémicos, etc.). Sin embargo, la extensa investigación realizada desde las ciencias sociales muestra que las personas perciben varias dimensiones de pérdidas o daños (aparte de las referidas a la salud y al medio ambiente), como las pérdidas económicas, las socioculturales o las político-institucionales. Las actitudes y las respuestas sociales ante los riesgos a menudo son producto de una mezcla de percepciones de dicho conjunto de dimensiones.

Aunque no es este el lugar para profundizar en ello, dichas dimensiones económicas, socioculturales y político-institucionales resultan claves para la comprensión de las respuestas sociales a los riesgos. Por definirlas brevemente, la dimensión económica del riesgo se refiere a las pérdidas económicas que potencialmente se pueden ocasionar en una situación de riesgo. Incluyen todo tipo de bienes y servicios susceptibles de ser valorados económicamente, y existe una larga tradición de cálculos de costes y beneficios y similares para realizar estimaciones de las posibles pérdidas económicas en situaciones de riesgo (Layard y Glaister, 1994). Los daños socioculturales, por su parte, remiten a la esfera de las relaciones sociales cotidianas, de los valores compartidos, de las identidades sociales, etc. La presencia de un riesgo ambiental o tecnológico puede ser percibida como una amenaza a la red de relaciones sociales de 
una población (Douglas, 1996) y, aunque no existan daños a la salud, dicha población puede reaccionar de manera conflictiva ante la gestión del riesgo. Finalmente, las dimensiones politico-institucionales del riesgo aluden a las interrelaciones entre instituciones y ciudadanos, a la percepción de injusticias, inequidades, etc. en la gestión del riesgo. En estas dimensiones, la noción de confianza es clave, pues se entiende que, al expresar un juicio sobre un riesgo, implícitamente efectuamos una evaluación de las instituciones que lo promueven, lo gestionan y lo regulan, por lo tanto, generamos un juicio sobre la confianza que estas nos merecen (Wynne, 1996).

En definitiva, las diferencias de sobreestimación o de minusvaloración entre expertos y legos, así como las respuestas sociales ante el riesgo en general, están atravesadas por varias dimensiones sociales que los cálculos expertos no suelen contemplar, pero que resultan fundamentales para entender las situaciones de riesgo. Veamos, a continuación, cómo evolucionaron las principales aportaciones al estudio de la percepción y la comunicación del riesgo desde las ciencias sociales, y cómo han ido emergiendo indicios de aquellas dimensiones sociales subyacentes a los procesos de percepción y gestión del riesgo desde su origen, hasta configurar el variado panorama actual.

\section{Los orígenes de la investigación en percepción del riesgo y el debate sobre el riesgo aceptable}

La preocupación pública en torno al riesgo tecnológico empieza a manifestarse activamente coincidiendo con el despliegue de las primeras aplicaciones comerciales de la energía nuclear civil, durante las décadas de 1960 y 1970. Es un momento en el que todavía impera el optimismo tecnológico y en el que se consolida la necesidad de evaluar científicamente los posibles riesgos asociados a tal desarrollo. Como describe Leiss (1996), en aquel contexto histórico, el análisis del riesgo se configura como una herramienta esencial, pues, para funcionar adecuadamente en un mundo de crecientes oportunidades tecnológicas, resulta indispensable evaluar y gestionar los riesgos con la mayor precisión. Se produce, así, la expansión de los denominados análisis de riesgo, centrados en evaluar, a través del análisis probabilístico y estadístico, la posibilidad de ocurrencia de los riesgos derivados de los avances tecnológicos. Demostrar científicamente la seguridad de estas nuevas instalaciones tecnológicas se convierte en prioridad fundamental.

Sin embargo, a pesar de los resultados y de las estimaciones derivadas de las intensas y costosas investigaciones en el ámbito de la seguridad, la preocupación y el rechazo social continuaban aumentando. El incremento en la oposición pública no era proporcional al de los niveles objetivos de riesgo que reflejaban los análisis de seguridad. El paradigma de este tipo de actividad, que la población considera arriesgada en mucha mayor medida que los expertos, sería precisamente la energía nuclear, en todas las fases del ciclo del combustible y, especialmente, en el caso de los residuos (Flynn et al., 1993). Emerge, por tanto, la necesidad de explicar a qué se debía una diferencia tan marcada entre 
los juicios de los expertos y los del público. Aunque, en un primer momento, no se concedió excesiva importancia a esta cuestión, a medida que los conflictos sociales adquirían mayor protagonismo, se reconoció que la "percepción social del riesgo» era una cuestión que requería atención, pues en ella parecían situarse las claves de las discrepancias entre expertos y público. Además, este interés por la percepción del riesgo respondía en gran medida a la necesidad de distribuir adecuadamente los recursos, especialmente los económicos, así como a la necesidad de hacer rentables las crecientes inversiones en seguridad (Prades y González, 1999).

En aquellos momentos, tuvo lugar el accidente nuclear de Three Mile Island (1979) y, aunque el alcance «objetivo» que tuvo (número de heridos, defunciones, daños a la propiedad) fue limitado, las repercusiones económicas y sociales fueron enormes y acabaron cuestionando el futuro de esta fuente de energía. Se constató, entonces, la enorme importancia de los "costes añadidos" al propio accidente, tales como la estigmatización de áreas con instalaciones peligrosas, el impacto sobre la vida económica y mercantil local, el descenso del valor de las viviendas, el incremento en los costes de los seguros, etc.

Ante esta situación, las primeras explicaciones de expertos e industria hicieron referencia a la falta de información «objetiva» del público y al papel de los medios de comunicación, que sobreestimaban el riesgo y se situaban en una posición de confrontación respecto a la industria. Se presupuso que el público, simplemente, no poseía conocimientos válidos y mostraba una actitud irracional ante los riesgos tecnológicos e industriales, mientras que infravaloraba otros riesgos claramente relevantes, como el de conducir sin cinturón de seguridad o el de fumar. Este modelo se ha conocido como el modelo del «déficit» y asume que, a mejor información, menor rechazo ciudadano a la tecnología.

En este sentido, los primeros trabajos sobre percepción del riesgo se centraron en estudiar los sesgos cognitivos de la ciudadanía respecto a los juicios expertos al valorar los riesgos originados por diversas tecnologías. Se pensaba que, una vez conocidos estos sesgos, se podría fomentar una mejor comprensión de aquellos fenómenos. Por supuesto, por «comprensiones adecuadas», se entendía solo aquellas que coincidieran con las formuladas por los expertos. La investigación sobre percepción del riesgo partía, pues, de la creencia de que se podría identificar objetivamente un nivel de riesgo aceptable, que ayudara a gestionar tecnologías peligrosas.

Se suele considerar (Espluga, 2004a; Prades y Solà, 2004; Puy, 1995) que el debate sobre el llamado «riesgo aceptable» empezó con el artículo publicado por Starr (1969) en la revista Science. El artículo presentaba un estudio sobre la aceptabilidad social de distintas fuentes de riesgo y desarrollaba un método de evaluación del nivel aceptado de riesgo en relación con los beneficios producidos por la tecnología. Con esta propuesta, Starr intentó ofrecer bases científicas para establecer umbrales de riesgo aceptable que se pudieran utilizar normativamente en la toma de decisiones. Para ello, elaboró un método basado en las preferencias (revealed preferences) deducidas a partir de la observación de los comportamientos ciudadanos, presuponiendo que, a través de pruebas y 
errores, la sociedad era capaz de alcanzar un equilibrio óptimo entre riesgos y beneficios asociados a cada actividad o tecnología. Por ejemplo, si, durante un período determinado, la ciudadanía no protestaba ante los riesgos derivados de los automóviles, la tasa de mortalidad anual provocada por ellos se podría considerar como la aceptada por la sociedad y, por tanto, un indicador del nivel de riesgo aceptable. Starr argumentaba que «la sociedad» establece un nivel aceptable de riesgo mediante la contrastación permanente entre daños y beneficios, de tal manera que, cuantos más beneficios genere una actividad, más aceptable será el riesgo asociado a ella. Starr realizó también numerosos cálculos a partir de registros estadísticos y observó que los riesgos asumidos voluntariamente (como conducir, esquiar o nadar) presentaban niveles de aceptación mucho más altos que los riesgos impuestos (como la contaminación atmosférica o los residuos radioactivos) e interpretó este postulado como una ley universal.

Estos planteamientos de Starr pronto fueron contestados y rebatidos desde varios puntos de vista. Otway y Cohen (1975) replicaron a Starr que sus datos empíricos eran poco consistentes y, además, cuestionaron las asunciones subyacentes a las "preferencias» tácitas que él atribuía a la «sociedad», en especial, la suposición de que la ausencia de protesta activa contra alguna tecnología en particular implicara su aceptación. También pusieron en cuestión la validez de la distinción entre riesgos voluntarios e involuntarios, ya que algunas personas pueden asumir un riesgo voluntariamente, mientras que, para otras, ese mismo riesgo puede ser inevitable (por ejemplo: conducir). Por otra parte, existen riesgos que, pese a ser considerados socialmente inaceptables, son tranquilamente aceptados por individuos concretos (como el tabaco o el tráfico). En este sentido, es importante distinguir entre los niveles de riesgo que una persona está dispuesta a aceptar en sus actividades cotidianas y los niveles que la colectividad está dispuesta a aceptar como coste asociado a la generación de un bien público, lo que el marco teórico propuesto por Starr no contemplaba.

No obstante, la crítica fundamental al concepto de riesgo aceptable radica en la consideración de que lo que se acepta no son riesgos, sino opciones, y el riesgo es solo una característica, entre otras, a la hora de evaluar y elegir entre aquellas opciones (Fischhoff et al., 1981). Cuando unos ciudadanos juzgan un riesgo tecnológico determinado, no solo consideran posibles daños que este pueda causar, sino que también valoran muchos otros factores asociados a esa actividad o tecnología (cómo afectará a sus vidas cotidianas, qué dependencia tienen de la empresa o de la institución que la promueve, a qué deberán renunciar, qué alternativas tienen, etc.). La relación entre percepción del riesgo y aceptabilidad no es directamente proporcional ni estrictamente causal. Es posible, por ejemplo, que aunque la magnitud percibida del riesgo sea pequeña, la fuente se considere inaceptable por otras razones o factores, como los que forman parte de las dimensiones sociales, culturales, políticas e institucionales mencionadas más arriba.

Como veremos a continuación, a partir de la década de 1980, las tradiciones teóricas del paradigma psicométrico o de la teoría cultural aportaron una 
importante batería de conocimientos que serían el embrión de las dimensiones sociales del riesgo mencionadas en el apartado anterior.

\section{La percepción del riesgo desde el paradigma psicométrico}

Desarrollado por el Grupo de Oregón y basado en numerosos estudios empíricos, el llamado paradigma psicométrico pretende explicar por qué algunos fenómenos generan alta ansiedad y temor, mientras que otros dejan indiferentes, así como las discrepancias entre las reacciones de los diversos grupos sociales, especialmente entre expertos y legos (Fischhoff et al., 1978; Irwin y Wynne, 1996; Krimsky y Golding, 1992; Pidgeon et al., 2003).

El enfoque psicométrico constituye la perspectiva más prolífica en el estudio de la percepción social del riesgo. Esta corriente parte de la tradición de la psicología cognitiva y de las teorías de la decisión racional y, además, incorpora una concepción multidimensional del riesgo (considera que las posibles consecuencias de los riesgos no son solo físicas, sino también psicológicas: miedos, temores, pérdidas sociales, etc.) (Slovic, 1993). Este enfoque considera que la comprensión intuitiva del riesgo es un concepto multidimensional que no puede ser reducido a un simple producto de probabilidades y consecuencias, sino que debe integrar otros factores relacionados con todos los efectos indeseables que la ciudadanía puede asociar con una causa específica. Si estas relaciones de causa-efecto reflejan o no la «realidad», es irrelevante, porque se considera que los individuos responden de acuerdo con su percepción del riesgo y no de acuerdo con un nivel objetivo de riesgo valorado científicamente.

$\mathrm{Su}$ aproximación metodológica es cuantitativa e implica la evaluación de una serie de riesgos, previamente elegidos por el equipo investigador, en función de ciertas características cualitativas. Assí, el paradigma psicométrico ha constatado que, efectivamente, la percepción del riesgo se relaciona con ciertas características de los peligros, entre las que destacan: el grado de familiaridad, el nivel de conocimientos, la sensación de control, la sensación de temor, el potencial catastrófico del fenómeno, etc., a lo que siempre es necesario añadir los beneficios asociados a la actividad que da lugar al riesgo. La investigación ha demostrado que muchas de estas características relevantes están íntimamente relacionadas entre sí, de forma que las dimensiones detectadas por el Grupo de Oregón podrían agruparse en dos factores básicos (Slovic, 1993, 1996). El primero podría etiquetarse como potencial catastrófico y agrupa las siguientes variables: incontrolabilidad, pánico, consecuencias fatales, alto riesgo para las generaciones futuras, difícil de reducir e involuntariedad. El segundo factor sería el grado de conocimiento o de familiaridad acerca del riesgo compuesto por las variables, inobservable, desconocido para aquellos expuestos a él, novedad y desconocimiento de la ciencia. Además, se detectó un tercer factor: el número de gente expuesta. Trabajos e investigaciones posteriores han permitido identificar un importante número adicional de variables significativas (Covello, 1985), también susceptibles de ser agrupadas en factores clave. 
Pero el concepto de riesgo que utiliza el enfoque psicométrico también presenta limitaciones. Turner y Wynne (1992) argumentaron que atributos como la controlabilidad, la familiaridad o la equidad en su distribución se interpretan mejor como «propiedades inherentes a las estructuras sociales-institucionales de los procesos de generación del riesgo, que como propiedad del riesgo en sí». Es decir, estos autores postulan que el paradigma psicométrico asume demasiado fácilmente la existencia objetiva e independiente del riesgo, al margen de los complejos contextos sociales en los que se experimenta.

Otra de las limitaciones que se atribuye a esta perspectiva es de tipo metodológico (Renn, 1992; Wynne, 1992). La amplitud o diversidad de las dimensiones que los individuos usan para formular sus juicios, así como su dependencia de heurísticos intuitivos y de conocimiento anecdótico, hace difícil agregar las preferencias individuales y buscar un denominador común que permita comparar percepciones individuales del riesgo. Además, los estudios de tipo cuantitativo sobre percepciones públicas del riesgo, inconscientemente, presuponen cuál es el significado del riesgo que tenemos en mente. A pesar de que se presentan como estudios dirigidos a identificar el modo en que los individuos perciben los riesgos, en la práctica, intentan medir las actitudes públicas respecto a unos significados impuestos del riesgo, sin cuestionar primero si la población participa o no de ese significado.

\section{La percepción del riesgo desde la teoría cultural}

Los partidarios del paradigma psicométrico sugieren que las estructuras y las estrategias cognitivas de las que hacen uso los sujetos son constantes y no varían a lo largo de las culturas ni de los grupos (Sjöberg, 1998; Sjöberg et al., 2004). Así, la idea de que los sujetos aprenden a temer ciertos riesgos en función de diferentes estilos de vida no encuentra demasiada cabida en aquel enfoque (Bostrom et al., 1992).

La teoría cultural del riesgo (Douglas y Wildavsky, 1982; Wildavsky y Dake, 1990) postula que la percepción del riesgo ha de considerarse como un proceso en el que cada grupo social elige selectivamente sus propios riesgos, poniendo especial énfasis en unos y restando importancia a otros. Este proceso de selección no se basa necesariamente en la evidencia científica ni tampoco en cuestiones primarias como la seguridad personal o medioambiental. En última instancia, las preocupaciones y los temores ante el riesgo constituyen mecanismos de control de las relaciones sociales, de cohesión de grupo social, que actúan de acuerdo con diversos patrones de interacción social.

Desde esta perspectiva, las instituciones seleccionarían y utilizarían los riesgos para controlar la incertidumbre de la conducta humana, para reforzar normas y facilitar la coordinación. Según Douglas (1996), la amenaza de una catástrofe cumple la función de activar ciertos mecanismos para renovar el compromiso de los miembros con los objetivos de la organización. Así, por ejemplo, se apela a la fragilidad o a la vulnerabilidad de la naturaleza para cohesionar la institución mediante la inculpación de un enemigo externo al 
grupo. El riesgo es, pues, un mecanismo de coacción para asegurar la sumisión de los miembros al sistema, y los riesgos reconocidos ejercen funciones de mantenimiento de este sistema. La cuestión, para Douglas, no es tanto qué riesgos son más alarmantes, sino cuáles pueden funcionar de manera más eficaz para cohesionar los diversos grupos sociales o sociedades.

Las observaciones de la teoría cultural de Douglas y Wildavsky (1982) se estructuran en un esquema analítico conocido como "análisis de red / grupo» (grid /group analysis), en el que la dimensión de "grupo" hace referencia al grado de identificación de una persona con un grupo social determinado, mientras que la dimensión «red» se refiere a cómo está distribuido el poder dentro del grupo (si es más o menos jerárquico). A partir de este esquema, los autores identifican diferencias entre grupos que posean diferentes «estilos de vida»: sesgos culturales o cosmovisiones (valores y creencias compartidas por los miembros del grupo) asociadas a los patrones de interacción social, como el igualitario, el jerárquico o el individualista. Los sesgos culturales y el tipo de relación social modulan la atención selectiva al riesgo, fortaleciendo el estilo de vida propio y oponiéndose al resto. Cada tipo de estilo de vida engendra un rango de posibles peligros (Dake, 1991). Los jerárquicos, por ejemplo, valoran el orden establecido, confían en los expertos y temen los desórdenes sociales y las conductas desviadas; los individualistas, sin embargo, valoran el logro de metas personales y acentúan el incentivo económico en el trabajo, pero temen la guerra y las crisis económicas; por su parte, los igualitarios desconfían de las instituciones y sus expertos, a quienes consideran motivados por puro egoísmo, obstáculos para el desarrollo de la sociedad igualitaria, adoptando actitudes reticentes hacia los riesgos tecnológicos. Douglas y Wildavsky (1982) sugieren que la percepción del riesgo y los comportamientos respecto a los riesgos tienen que ver con su socialización en alguna de estas tipologías culturales.

Entre las críticas a este esquema analítico, destaca la dificultad de aplicarlo de modo empírico, ya que, por un lado, es muy difícil determinar a qué nivel de organización social se puede aplicar (grupos pequeños o grandes sociedades) $y$, por otro, como solo se proveen dos valores (alto y bajo) para cada dimensión, no resulta fácil dar cabida a situaciones reales (Turner y Wynne, 1992). En este sentido, cabe destacar que no existe consenso entre los autores de esta teoría a la hora de decidir si unos individuos concretos se engloban dentro de una u otra de las culturas determinadas. Algunos autores, como la propia Douglas, proponen una interpretación rígida y entienden que la pertenencia a una cultura es una característica permanente de la persona. Otros autores, como Wildavsky, han acabado por considerar que cada individuo puede ser adscrito a diferentes culturas en función de cada contexto de interacción social donde se encuentre. Además, la mayor parte de los estudios empíricos que han intentado aplicar el esquema analítico de la teoría cultural del riesgo han utilizado técnicas de recogida de datos cuantitativas, mediante cuestionarios. Esto ha permitido sistematizar una serie de ítems aplicables a diversas sociedades, pero ha propiciado una baja capacidad para introducir matices locales y captar la multidimensionalidad de los procesos de percepción del riesgo. 
Finalmente, hay que remarcar que se trata de un esquema bastante rígido, que deja poco margen a la acción reflexiva de los individuos y que, en cierto modo, presupone una realidad estática y obstaculiza pensar el cambio. No obstante, en cuanto al tema que nos ocupa, su virtud radica en proponer una explicación a la percepción del riesgo basada en los sistemas de valores de las sociedades, incorporar la noción de justicia al debate del riesgo y explicar las limitaciones de las perspectivas que privilegian, sin matices, las decisiones de los expertos.

\section{La percepción del riesgo desde perspectivas reflexivas e interpretativas}

A continuación, se describen las perspectivas teóricas que han intentado desarrollar un marco teórico más amplio e integrador, recogiendo elementos de las propuestas anteriores y articulándolos en unos modelos más sensibles a los contextos de interacción y a los procesos psicosociales e institucionales en los que se experimentan los riesgos. Las últimas dos décadas han visto el desarrollo de un conjunto de investigaciones que se podrían agrupar en la denominada "sociología interpretativa del riesgo», fruto de los debates que, desde mediados de 1990, pretendían encontrar un enfoque alternativo a las corrientes entonces dominantes.

De manera general, el paradigma psicométrico se centró en la medición de atributos subjetivos de los factores de riesgo, y la teoría cultural, en procurar entender los comportamientos de riesgo en términos de estilos de vida o adscripciones culturales. Ambas perspectivas han afrontado considerables retos conceptuales, e incluso ha habido fructíferos intentos de combinarlos con resultados interesantes (Marris et al., 1996, 1998; Sjöberg, 1998; Slovic y Peters, 1998). Sin embargo, las limitaciones metodológicas de ambos enfoques son difíciles de resolver, pues el tiempo ha puesto de manifiesto que las técnicas de cuestionario, por sí solas, no son capaces de capturar la complejidad de las percepciones del riesgo en contextos sociales específicos. Esta evidencia sugiere la necesidad de utilizar métodos más sensibles al contexto (Horlick-Jones et al., 2003).

Por otra parte, ciertos autores han problematizado la existencia de diferencias netas entre la noción de "experto" y la de "público lego», ya que ambos cuentan con sus propios sesgos cognitivos, interdependencias sociales y adscripciones culturales (Horlick-Jones et al., 2003; Wynne, 1996). Todo ello cuestiona algunas de las categorías básicas de la investigación clásica en percepción del riesgo.

La investigación interpretativa ha pretendido afrontar estas dificultades centrando la atención en las formas de dar sentido a las situaciones de riesgo. La sociología interpretativa del riesgo se fundamenta en epistemologías interaccionistas, tradiciones hermenéuticas y metodologías próximas a la investigación etnográfica (Fitchen et al., 1987; Macgill, 1987, Zonabend 1993; Irwin et al., 1996, 1999; Walker et al., 1998). Todas estas perspectivas reconocen la centralidad de la interpretación y de los significados en la conformación de las interacciones sociales, y privilegian un tipo de investigación social más 
receptiva a las lógicas específicas que estructuran las prácticas de las personas y el sentido que estas les otorgan.

Desde esta aproximación, la investigación sobre la percepción del riesgo no debería dedicarse tanto a identificar las percepciones del riesgo real u objetivo, sino a averiguar las lógicas o racionalidades de la vida cotidiana desde las que la ciudadanía identifica y experimenta los riesgos, las actividades que los generan y las instituciones que los gestionan (Turner y Wynne, 1992; Horlick-Jones, 2005). Esto implica también que los estudios realizados desde esta perspectiva deben tener muy en cuenta la posición social de los agentes implicados en la gestión del riesgo, su ubicación en la estructura social, sus recursos y sus relaciones de poder. Así, por ejemplo, en uno de sus primeros estudios y mediante observación participante, Wynne $(1980,1982)$ investigó el caso de los conflictos sociales relacionados con la potencial contaminación generada por la planta tecnológica de Windscale (Sellafield-Windscale Nuclear Complex) en Gran Bretaña, y concluyó que uno de los principales factores para valorar el riesgo al que la población que se percibía expuesto era la percepción de los agentes controladores (funcionarios del gobierno, técnicos de seguridad, etc.): si se detectaba secretismo, arrogancia o incompetencia, la evaluación del riesgo era mucho mayor de lo que indicaban los cálculos expertos. Así, la percepción de riesgo y los comportamientos relacionados pueden entenderse como incrustados en una matriz de asociaciones cotidianas, de formas preferidas de la vida, de relaciones de confianza, de limitaciones económicas y de compromisos emocionales (Alaszewski y Horlick-Jones, 2003; Espluga, 2005; Prades López et al., 2008).

En definitiva, el enfoque interpretativo centra su atención en las lógicas situacionales específicas en las que acontecen los razonamientos y las prácticas sobre el riesgo, a lo largo de una variedad de contextos sociales y organizacionales. Horlick-Jones y Prades (2009) señalan que esta perspectiva de investigación ha realizado importantes aportaciones al estudio de la naturaleza de los razonamientos prácticos sobre el riesgo, como, por ejemplo:

- La relevancia de las prácticas de presentación de la persona en la vida cotidiana (social accounting practices) en la conformación de los relatos y de las prácticas sobre el riesgo: en situaciones socialmente problemáticas necesitamos presentarnos como "personas razonables», con las implicaciones que ello conlleva en términos de culpa y responsabilidad.

- La importancia del (limitado e imperfecto) conocimiento que solemos tener sobre los riesgos que pretendemos comprender (low information rationality), así como el carácter dinámico de nuestro modo de razonar y de dar sentido al riesgo (que puede variar a medida que conocemos más sobre él).

— La importancia de la "firma» (signature) de la tecnología, es decir, de cómo las características materiales de los riesgos se articulan en los razonamientos prácticos de los diversos actores sociales.

- La relevancia de métodos y técnicas que provean una "descripción densa» (thick description, en el sentido de Ryle, 1971) para abordar los detalles 
específicos de la situación de riesgo y entender la significación social subyacente a las acciones llevadas a cabo por los actores.

En esencia, la investigación interpretativa sugiere que nuestras respuestas ante el riesgo no son meramente calculadoras e instrumentales, sino que reflejan la especificidad del riesgo en cuestión y de los contextos en que dicho riesgo acontece. Estos contextos integran una compleja interacción de expectativas sociales, compromisos y maneras de comprender las situaciones de riesgo, que es necesario identificar y ordenar para poder entender las percepciones de riesgo (Petts et al., 2001; Horlick-Jones y Prades, 2009). Esta aproximación permite integrar en un mismo análisis todas las dimensiones relacionadas con los procesos de riesgo, incluidas las económicas, las socioculturales o las políticoinstitucionales mencionadas en un apartado anterior.

\section{La evolución de la comunicación del riesgo}

De la misma manera que la investigación en "percepción del riesgo" ha ido evolucionando desde perspectivas más simples y restrictivas hacia paradigmas más complejos, la "comunicación del riesgo" ha sufrido un proceso similar y paralelo. Así, durante las décadas de 1970 y 1980, se promovieron multitud de medidas políticas encaminadas a reducir las diferencias entre las percepciones de expertos y público lego, principalmente bajo la fórmula de campañas informativas. Estas aproximaciones se diseñaron bajo el paraguas conceptual del modelo del déficit cognitivo, un concepto que presupone que son los expertos quienes tienen la mejor y más objetiva información sobre el riesgo, mientras que el público es ignorante o no tiene la información necesaria para entender la situación, y que por ello se le ha de proveer de la información correcta.

Esta fue la aproximación predominante desde la década de 1970 y la que dio lugar al creciente protagonismo de la investigación en comunicación del riesgo. Los responsables de empresas y de instituciones políticas consideraban evidente que, para evitar aquellas creencias irracionales y aquellos comportamientos inadecuados, se debía informar correctamente a la ciudadanía sobre la bondad de las investigaciones y los análisis técnicos sobre riesgos. Había que comunicar los riesgos correctamente, lo cual no era obvio ni evidente. Sin embargo, pronto se constató que no existe una relación causal directa entre la información que las personas tienen sobre los riesgos y los comportamientos que ponen en práctica ante ellos (Irwin et al., 1999). Es a partir de la década de 1990 cuando se empieza a poner el énfasis en perspectivas de carácter más holístico y multidimensional, que tienen en cuenta los marcos social, político y cultural en los que se desarrollan los procesos de percepción y comunicación de los riesgos (Gonzalo y Farré, 2011; Pidgeon et al., 2003; Poumadère, 2008).

En la década de 1990, van apareciendo normas y directrices que promueven la mejora de la gestión del riesgo mediante el establecimiento de medidas de información pública, hasta el punto de que esta cuestión se convierte en un punto central y clave de los estudios y la práctica de la gobernanza del riesgo. 
Las renovadas directivas europeas Seveso (de 1996), que exigen a las empresas químicas una política informativa real, o el Convenio de Aarhus (de 1998), sobre la obligación de las administraciones estatales de dar información al público acerca de temas ambientales, son un buen ejemplo de esta tendencia.

En paralelo, se observa un incremento de las exigencias y las reclamaciones de información sobre la exposición pública a riesgos tecnológicos y ambientales. Con frecuencia, los ciudadanos piden más información, una demanda que a menudo tiende al infinito, o se quejan de tener dificultades para interpretarla y darle sentido. Estas reclamaciones no dejan de proliferar, a la vez que la información de los medios de comunicación tiende a ser considerada de baja calidad y no siempre digna de tener en cuenta (Barnett, 2008).

A mediados de la década de 1990, el psicólogo Baruch Fischhoff (1995: 138) ya sintetizó la evolución de los presupuestos de la comunicación sobre riesgos tecnológicos y ambientales de la siguiente manera (secuencia cronológica):

1. Todo lo que debemos hacer es tener los datos correctos.

2. Todo lo que debemos hacer es comunicar los datos a los ciudadanos.

3. Todo lo que debemos hacer es explicar qué significan los datos.

4. Todo lo que debemos hacer es mostrarles que han aceptado riesgos similares en el pasado.

5. Todo lo que debemos hacer es mostrarles que es un buen negocio para ellos.

6. Todo lo que debemos hacer es tratarlos bien.

7. Todo lo que debemos hacer es incluirlos como miembros del proceso de decisión.

8. Todo lo que debemos hacer es todo lo anterior (puntos del 1 al 7).

Este listado de recomendaciones se lee de forma secuencial y refleja bastante bien la historia de la comunicación del riesgo, que pasa de una exclusión inicial del público, a detectar la necesidad de mantenerlo informado, a tener en cuenta dimensiones sociales que van más allá de las cognitivas para generar confianza, hasta incluir la visión del público en el proceso de definición y gestión del riesgo.

Dos décadas y media después de que Fischhoff lo sintetizara por escrito y con un amplio eco en los círculos estudiosos de esta materia, en la práctica, todavía nos encontramos con demasiados casos donde los gestores de los riesgos ignoran (o aparentan ignorar) esta evolución de comunicación del riesgo, lo que quizá sea un indicador de las dificultades para implementar la participación e implicación ciudadanas en las políticas ambientales y/o de gestión de riesgos.

No obstante, en los últimos años, se siguen generando propuestas teóricas y prácticas encaminadas a una efectiva comunicación del riesgo. Así, por ejemplo, el enfoque de la amplificación social del riesgo (SARF en su acrónimo en inglés) (Pidgeon et al., 2003) es un modelo desarrollado por los investigadores de la Clark University (Kasperson, Kates, Renn y otros) junto a algunos autores del enfoque psicométrico del Decision Research Group de Oregon 
(Slovic y otros). El concepto de amplificación social del riesgo sostiene la tesis de que los acontecimientos relacionados con riesgos interactúan con procesos psicológicos, sociales, institucionales y culturales, en formas que pueden amplificar o atenuar las percepciones del riesgo, así como modular el comportamiento ante el riesgo (Kasperson et al., 1988). Según este modelo, el proceso de amplificación social del riesgo comienza con algún evento (por ejemplo: un accidente) o con algún informe sobre posibles daños ambientales o en la salud. Ciertos grupos o individuos incluyen el evento en su agenda, seleccionan aquellas características específicas que se adaptan a sus percepciones y esquemas mentales, y comunican sus interpretaciones a otros individuos y grupos. Finalmente, reciben interpretaciones de retorno, con lo que algunos pueden cambiar sus creencias previas, ganar conocimientos y perspicacias adicionales o verse motivados para pasar a la acción; otros pueden reafirmar sus puntos de vista, y otros recomponer nuevas interpretaciones y reenviarlas a las fuentes $o$ a otras partes interesadas. $\mathrm{Al}$ recoger información sobre riesgos y comunicarla a otros (explícita o implícitamente), los individuos, las instituciones o los grupos actúan como estaciones de amplificación (Kasperson, 1992).

Hasta el momento, la amplificación social del riesgo se ha utilizado para estudiar procesos de comunicación del riesgo, así como para explorar las relaciones entre las respuestas individuales, sociales y políticas (Pidgeon et al., 2003). Se trata de un modelo dinámico que se diferencia de los modelos tradicionales de comunicación basados en la simple transmisión de información entre un receptor y un emisor, y que enfatiza los mecanismos de amplificación que pueden producir cambios en los mensajes (Renn, 1991, 2003). Sin embargo, las dificultades para contrastarlo empíricamente han dado lugar a que la amplificación social del riesgo se considere más un marco descriptivo de la percepción social del riesgo y de los procesos de comunicación que una teoría aplicable y verificable en sentido estricto.

Otro enfoque interesante en este contexto es el modelo de Escenarios Múltiples del proceso de Comunicación del Riesgo (ERiK), desarrollado por el Federal Institute for Risk Assessment, de Alemania (Hertel y Henseler, 2007). ERiK parte del supuesto de que la comunicación del riesgo se produce en un contexto donde múltiples actores, con una oferta plural de valores, entran en conflicto para definir el riesgo a diferentes niveles. Se trata de un modelo teórico y práctico estructurado en diferentes escenarios comunicativos, en los que puede estar involucrada cualquier institución pública. Distingue entre una comunicación horizontal (entre los actores que tradicionalmente participan en el proceso regulador del riesgo) y una comunicación vertical (que permite integrar argumentos de personas e instituciones situadas fuera de los procesos tradicionales de regulación). Estas dos vertientes permiten introducir preocupaciones y valores que garanticen la pluralidad del proceso y mejoren su legitimidad. Por otro lado, ERiK identifica cuatro escenarios principales: la comunicación en y entre agencias públicas, la comunicación con los expertos, la comunicación con las personas afectadas por el proceso y la comunicación con el público en general. La finalidad última es diseñar un proceso de comu- 
nicación del riesgo que integre los diversos intereses y puntos de vista, con una importante dimensión participativa.

Otro modelo de este tipo es el denominado Stakeholders in Risk Communication (STARK) (Wright, 2006), el cual plantea dibujar un marco en el que las personas afectadas, los medios de comunicación y el público se integren y participen en el desarrollo de una gestión más dinámica de los asuntos públicos, para garantizar así el diálogo entre todas las partes interesadas. Para ello, se apuesta por una estrategia institucional de comunicación del riesgo que vaya más allá de la simple transmisión de información, al considerar que la comunicación de riesgo no es efectiva si no implica un esfuerzo por integrar, asimilar y comprender el punto de vista del otro. El objetivo final es generar una cultura de entendimiento e integración a partir de la gestión institucional de la participación de los diferentes actores. Desde este punto de vista, un buen proceso de comunicación del riesgo implicaría una serie de fases estructuradas en forma de bucle (del análisis a la mejora, pasando por el diseño, la aplicación o la monitorización) que dan lugar a una espiral de gestión en la que se van añadiendo nuevas experiencias, para así mejorar el proceso en su conjunto.

Ambas propuestas (STARC y EriK) parten de la idea de que son las instituciones públicas las que deben implementar un proceso de comunicación de riesgo plural y participativo, donde todos los participantes puedan hablar y ser escuchados, de manera que se recoja y se integre una amplia variedad de valores, intereses y puntos de vista. Se trata de dos modelos fuertemente normativos, que establecen lo que "debería» hacerse para conseguir una buena comunicación del riesgo. Son, sin duda, propuestas valiosas para avanzar hacia una comunicación del riesgo más compleja y que integre las visiones de una multiplicidad de actores. Sin embargo, su aplicación a casos empíricos presenta algunas dificultades prácticas. Espluga et al. (2010), en un estudio sobre comunicación de riesgo químico, mostraron cómo la gran dependencia que unos actores tienen respecto a otros, tanto en términos materiales como simbólicos, comporta obstáculos difíciles de salvar. Las situaciones de riesgo son contextuales, y cada contexto marca las reglas mediante las que unos actores se relacionan con otros. Estas interacciones, a menudo, están conformadas por relaciones de poder muy marcadas, que impiden a los actores expresar sus preferencias de manera directa (de modo que, en sus conversaciones y discursos, acuden a circunloquios, metáforas, modelos de pensamiento o fórmulas discursivas condicionales para hablar de su percepción de riesgo), lo cual supone un reto metodológico que estos modelos soslayan con excesiva complacencia.

En este mismo sentido, Wardman (2008), después de analizar la copiosa bibliografía sobre comunicación del riesgo, identifica aproximaciones más normativas o más instrumentales, más participativas o menos, y concluye que es necesaria una visión de la comunicación del riesgo más contextualizada, que tenga en cuenta las dinámicas de poder subyacentes a su propia constitución.

A partir de la integración de varios de estos modelos teóricos, Gonzalo y Farré (2011) han propuesto un metamodelo para el análisis de la comunicación de riesgos. Para cada caso concreto, identifican a varios actores o "comuni- 
dades de riesgo» que intercambian información a través de diversos canales, en un gran juego de mediaciones que contribuyen a la definición del riesgo. Inspirados en la lógica de la estructuración de Giddens (1984), consideran la comunicación como parte constitutiva del proceso social de construcción de significado alrededor del riesgo, poniendo el énfasis en su potencialidad reflexiva: «Las instituciones definen y determinan en parte el significado del riesgo que acaba circulando reflexivamente entre los actores sociales que los resignifican. Se trata de encontrar el punto de contacto entre estas dos formas de construir comunicativamente el riesgo" (Gonzalo y Farré, 2011: 125). El concepto de "comunidad» remite a los actores sociales e institucionales que construyen un espacio propio para interactuar con el resto. Dentro de cada comunidad, existen lógicas propias y compartidas, aunque no son nunca completamente homogéneas y representan una gran variedad de opciones. Estas comunidades de riesgo pasan a ser comunidades de comunicación de riesgo a través de su influencia en la construcción discursiva del riesgo, a partir de su mediación estructural y sus múltiples mediatizaciones, tanto internas como externas. Así, el mapa dibujado por el metamodelo no es un espacio estático, sino un conjunto dinámico, permeable y en constante movimiento.

Los autores distinguen las siguientes comunidades: comunidad de agencias públicas, comunidad empresarial, comunidad de los científicos y expertos, comunidad de los medios de comunicación y comunidad social (Gonzalo y Farré, 2011). El metamodelo sitúa la "comunidad social» en el centro, para representar que el objetivo real de la comunicación de riesgo debiera ser la construcción democrática de significado alrededor de los temas que afectan a la sociedad en su conjunto. De esta manera, se pone el acento en su dimensión social y se rompe de raíz con las visiones más lineales e instrumentales.

En definitiva, el análisis de la comunicación de riesgo es un elemento crucial a la hora de diseñar modelos de gobernanza del riesgo, ya que la comunicación desempeña un papel central para dar cuenta de las interacciones entre actores. Los principales modelos de comunicación del riesgo, como el SARF, o los más participativos STARC o ERIK, son útiles para mostrar las dimensiones comunicativas de los procesos de riesgo, pero aún existen varios aspectos de estos procesos que permanecen ocultos si no se abordan adecuadamente las dimensiones interpretativas de las acciones humanas, como las prácticas de justificación social (social accounting practices), los razonamientos sobre el riesgo en contextos de información incompleta (low information rationality) o la singularidad material de las tecnologías que provocan el riesgo (signature).

Además, como han puesto de relieve Horlick-Jones y Rosenhead (2013), desde una perspectiva interpretativa, cualquier proceso de comunicación podría considerarse un intento de imponer a la audiencia una racionalidad («acreditada»), asumiendo, por tanto, que los gustos, las preferencias o los comportamientos de dicha audiencia son incorrectos o «irracionales». En este sentido, es imprescindible ser conscientes de la naturaleza política y moral de las estrategias de comunicación de riesgo. Los principales hallazgos de la investigación inter- 
pretativa y sus implicaciones para las estrategias eficientes de comunicación e implicación muestran la necesidad de que existan diseños institucionales «a medida" (Molotch, 2008), que contemplen la adecuada consideración de los «modos de razonar», de dar sentido a los riesgos y que consideren de modo apropiado las sensibilidades de los diversos actores implicados en los procesos de comunicación e implicación (Horlick-Jones y Prades, 2009).

\section{Hacia la gobernanza del riesgo y la implicación ciudadana en las políticas ambientales}

Gran parte de la bibliografía contemporánea sobre riesgo ha puesto sobre la mesa, tanto para gobiernos como para empresas, la necesidad de alcanzar una mejor comprensión de los públicos a los que se dirigen y de cómo estos dan sentido a los riesgos a los que están expuestos (practical reasoning) (HorlickJones et al., 2003; Otway, 1992; Petts et al., 2001; Renn, 2003, 2008; etc.). Como hemos visto, tanto las teorías sobre percepción social del riesgo como los enfoques sobre comunicación de riesgo han avanzado progresivamente hacia esta definición de la problemática. En el fondo, los procesos de gestión de riesgos y las respuestas sociales a los mismos revelan una disfunción en la toma democrática de decisiones.

Así, aunque la comunicación del riesgo continúa siendo un elemento crucial tanto para el sector público como para el privado, a partir de la década de 2000, la agenda pública se viene orientando, claramente, hacia planteamientos vinculados a la gobernanza y a la implicación de los actores protagonistas en la gestión del riesgo (Horlick-Jones, 2008): la gestión del riesgo se reconoce como un elemento esencial de un buen gobierno. Esta nueva orientación hacia la gobernanza del riesgo, en la práctica, se tradujo en dos modalidades superpuestas: gobernanza corporativa en el sector privado (responsabilidad social corporativa, y preocupación por el control y la seguridad) e implicación ciudadana y con personas afectadas por el proceso en el sector público. De esta manera, las cuestiones vinculadas a la transparencia, a las perspectivas de las partes interesadas o a las consideraciones éticas se incorporaron al discurso regulador (Horlick-Jones, 2005; Walls et al., 2004).

Los argumentos que proponen fórmulas de implicación de la ciudadanía en la gestión de los riesgos y en la elaboración de políticas ambientales provienen de un amplio rango de perspectivas, incluyendo el planteamiento normativo de extender la democracia; ideas vinculadas a la mejora de la calidad de los procesos de toma de decisión, así como argumentos corporativos centrados en implicar a las personas interesadas y a los accionistas. Además, encontramos la reciente tendencia entre los gobiernos a adoptar técnicas de gestión del ámbito privado como parte de lo que se viene denominando «nueva administración pública». Estos procesos han dado lugar a la hibridación de las perspectivas públicas y privadas en torno a las prácticas de gestión (Walls et al., 2004).

Horlick-Jones et al. (2007) repasan algunos de los argumentos más habituales a favor y en contra de los procesos de participación pública y de impli- 
cación ciudadana, muchos de ellos relacionados entre sí. Entre los favorables, encontramos los siguientes:

- Contribuyen a aumentar la credibilidad de las instituciones y a construir confianza pública.

- Contribuyen a legitimar decisiones.

- Mejoran la calidad de los procesos de toma de decisiones (por ejemplo: identificando posibles alternativas o considerando las implicaciones potenciales para los afectados).

- Permiten adquirir conocimiento sobre, y facilitar conocimientos a, los grupos de personas interesadas.

- Ayudan a despejar dudas en torno a la adopción de ciertas medidas políticas y a evitar o disminuir dificultades potencialmente caras.

- Promueven debates en profundidad sobre cuestiones que los gobiernos o las sociedades conciben como importantes.

Entre los argumentos de los detractores sobre los procesos de implicación, cabe destacar los siguientes:

- Resultan demasiado caros, en el sentido de que los costes no justifican los beneficios.

- Suelen requerir mucho tiempo.

- Pueden ocasionar "puntos muertos», en vez de agilizar salidas positivas.

- Pueden generar resultados triviales basados en consensos débiles o pobres entre personas interesadas con valores e intereses en conflicto.

- Pueden generar alarmas entre la población, así como mala publicidad y controversia, en lugar de evitarla.

- Pueden generar procesos «ficticios» (sin intención real de ejercer influencia en los procesos de toma de decisiones) o sesgados (en los que solo se contemplan los valores del poder político).

- La toma de decisiones tecnológicas y medioambientales suele tener una naturaleza compleja, para cuya comprensión no todo el mundo está preparado ni dispone de los conocimientos necesarios.

Evidentemente, todas estas consideraciones se relacionan con reflexiones más amplias sobre el papel de la ciudadanía en la toma de decisiones en la sociedad contemporánea. A pesar de que hay autores, como Mejlgaard (2009), que consideran que la participación ciudadana no es tan relevante -en lo que a la justificación social de la ciencia y la tecnología se refiere- y que, por tanto, el foco debe resituarse en la comunicación unidireccional, buena parte de la bibliografía sobre gobernanza del riesgo sugiere que la ciudadanía debería poder asesorar a los políticos ante decisiones sobre opciones tecnológicas, aun reconociendo que su saber técnico al respecto puede ser muy limitado. Esta es la postura que apela al compromiso normativo de extender la democracia y al reconocimiento de que el saber técnico es, también, limitado. Esto nos remite a las preguntas que planteábamos en la introducción del presente texto, sobre 
cómo tomar decisiones que sean percibidas como justas y legítimas en condiciones de incertidumbre. A lo largo de estas páginas, hemos dado suficientes indicios sobre cómo han evolucionado las respuestas a aquellas cuestiones, hasta llegar a las fórmulas comunicativas y participativas actuales.

\section{STAVE: una propuesta de implicación ciudadana en las políticas ambientales}

Para terminar, presentamos brevemente una innovadora aproximación a los procesos de implicación y participación ciudadana en la elaboración de políticas ambientales, desarrollada en el marco del proyecto europeo PACHELBEL (Policy Addressing Climate Change and Learning about Consumer Behaviour and Everyday Life; FP7, 2010-2012) y centrada en la búsqueda de métodos para comprender tanto las acciones del público como de los diseñadores de políticas, así como para conectar la esfera de la elaboración de políticas con la esfera de la vida cotidiana de las personas afectadas por aquellas.

La metodología STAVE (Systematic Tool for Behavioural Assumption, Validation and Exploration) se basa en la implicación de los actores clave por dos vías (Horlick-Jones y Prades, 2014; Prades et al., 2015). Por una parte, mediante procedimientos de investigación acción, se fomenta la implicación con las instituciones públicas responsables de elaborar e implementar políticas medioambientales, con el objetivo de entender el proceso de formulación de políticas «desde el interior» (acceso al backstage) (Horlick-Jones y Rosenhead, 2002, 2007). El método STAVE permite valorar el papel del conocimiento en contextos organizacionales (procesos de presentación, discusión y acuerdos sobre la realidad, razonamientos prácticos, uso de diferentes formas y fuentes de conocimiento, etc.) (Horlick-Jones, 2005; Horlick-Jones et al., 2007). El objetivo final es adquirir un conocimiento, próximo y amplio, de los aspectos prácticos y cotidianos del proceso de formulación de políticas públicas. Por otra parte, en paralelo, STAVE genera un proceso de implicación con grupos de ciudadanos con el objetivo de comprender los aspectos prácticos y cotidianos de su comportamiento en cuanto consumidores. STAVE genera procesos de deliberación en grupo (reconvened focus groups), combinados estratégicamente con una serie de herramientas (tool kit) diseñadas para promover una reflexión iterativa sobre diferentes tipos de discursos generados por las personas participantes. De esta manera, se pueden identificar elementos de las diferentes dimensiones del riesgo, así como observar su articulación en contextos y situaciones específicos.

El método STAVE se desarrolló en el marco del proyecto europeo PACHELBEL (FP7) y se aplicó en seis países (Alemania, España, Francia, Reino Unido, Rumanía y Suecia) para analizar diversas políticas ambientales: consumo doméstico de energía, movilidad, uso de redes eléctricas y contadores inteligentes, toma de decisiones para aislamiento térmico de edificios y para recambio de electrodomésticos. La evidencia recogida en los diversos países permite concluir que STAVE es una herramienta flexible (se puede aplicar en un amplio rango de contextos y situaciones) que fomenta el escrutinio 
crítico de los propios conocimientos y las prácticas cotidianas, tanto de los responsables públicos como de la ciudadanía. STAVE logra conectar la esfera de la elaboración de políticas con la de la ciudanía, lo cual genera nuevas vías de comunicación entre estas dos esferas de racionalidad, experiencia y acción. Finalmente, STAVE tiene la capacidad de enriquecer el proceso de elaboración e implementación de políticas medioambientales, al estimular la implicación de los responsables públicos con la realidad de la ciudadanía ${ }^{2}$.

El método STAVE está diseñado para que los gestores de un riesgo tecnológico o ambiental puedan autoanalizarse y ser conscientes de sus asunciones sobre las actitudes y los comportamientos de los ciudadanos, así como para que un grupo de ciudadanos se pueda implicar (public engagement) en la valoración de las decisiones y de los comportamientos de los gestores del riesgo (o policy-makers), así como en el análisis de su propia experiencia cotidiana. Para ello, STAVE cuenta con una serie de herramientas que permiten «traducir» el lenguaje de los responsables públicos para que sea inteligible por los ciudadanos y viceversa, todo ello en un tiempo breve y a un coste razonable (con lo cual se minimiza una de las críticas a los procesos participativos y de implicación ciudadana: que sean procesos costosos en recursos y en tiempo) ${ }^{3}$.

Hay que señalar que el método STAVE es efectivo en casos de problemas ambientales o riesgos tecnológicos sobre los cuales no exista un gran conflicto social, en el que los actores no hayan polarizado sus posiciones de manera irreconciliable. En este sentido, es un método más apropiado para situaciones de promoción de hábitos sostenibles, de exploración de prácticas cotidianas, de evaluación de políticas ambientales que pretendan influir en los comportamientos del público, etc., pero no tanto en casos de conflictos sociambientales de una cierta intensidad, pues, en estos casos, no es posible conseguir la implicación requerida, tanto por parte de los decisores públicos como de la ciudadanía.

\section{A modo de conclusión}

En la introducción de este artículo, formulamos una serie de cuestiones cruciales en términos de gobernanza del riesgo: ¿cómo gestionar el riesgo tecnológico cuando carecemos de evidencias científicas suficientes, pero necesitamos tomar decisiones inmediatas (permitirlos, prohibirlos, regularlos, etc.)? ¿Cómo implantar políticas ambientales y de sostenibilidad ecológica legítimas y necesarias? ¿Cómo elaborar políticas que integren las sensibilidades de los diferentes sectores sociales, tanto expertos como legos?

2. En la página web del proyecto PACHELBEL (http://www.pachelbel.eu), se puede encontrar una amplia información sobre la metodología y sobre los resultados de los estudios de caso realizados.

3. En el presente número monográfico, aparecen dos artículos que ilustran la aplicación del método STAVE. El de Espluga et al. trata sobre las prácticas sostenibles de una muestra de comerciantes de Barcelona en el marco de la Agenda 21 de la ciudad, y el de Konrad et al., sobre el consumo energético doméstico en el marco de una política ambiental de ahorro energético en Stuttgart (Alemania). 
De acuerdo con el escenario dibujado hasta aquí, tanto la gestión del riesgo como las políticas ambientales y de sostenibilidad ecológica deberían contemplar la multidimensionalidad de los procesos sociales en los que se experimenta el riesgo, y ello requiere de metodologías sensibles a las interacciones sociales y a los contextos particulares. Si bien, en las últimas cuatro décadas de investigación en percepción y comunicación de riesgos, se han realizado importantes aportaciones teóricas y prácticas, el tiempo ha hecho evidentes sus limitaciones y la necesidad de avanzar hacia propuestas más complejas e integradoras.

Durante la última década, estas propuestas se han ido subsumiendo en el amplio paraguas de la gobernanza del riesgo (Renn, 2008). Desde esta perspectiva, resulta indudable que la gestión de riesgos tecnológicos y ambientales supone un reto esencial en el que los ciudadanos se juegan la exposición a riesgos que pueden amenazar sus condiciones de vida, y las instituciones se juegan su aceptación pública y la legitimidad democrática de sus decisiones. De acuerdo con lo relatado en este artículo, existe cierto consenso en que la solución a semejante reto requiere mayor transparencia en la toma de decisiones y mayor participación e implicación ciudadana (public engagement) en la elaboración de políticas públicas. Ciertamente, no es un reto sencillo, e incluso se percibe con reticencias desde ciertos sectores empresariales e institucionales. Por ello, en las prácticas actuales de gestión de riesgos tecnológicos y ambientales, conviven varios de los modelos aquí reseñados, desde las aproximaciones meramente tecnocráticas con procesos de comunicación unidireccionales (top-down), pasando por procesos que incluyen algún tipo de comunicación bidireccional entre instituciones y grupos de interés, hasta modelos que procuran incluir los puntos de vista de la población a lo largo de todo el proceso de toma de decisiones. Aunque no se trata aún de la práctica generalizada, cada vez se extiende más la visión participativa, particularmente a nivel local (Renn, 2006), y cada vez son más las propuestas metodológicas para abordarlo, como el método STAVE. De no avanzar por esta vía, no será fácil evitar que se produzcan y se perpetúen los desajustes entre las medidas políticas propuestas y las decisiones y las acciones cotidianas de la población, lo cual redunda en un incremento de la exposición a riesgos y de las prácticas ecológicamente poco sostenibles.

\section{Agradecimientos}

Este artículo forma parte de los resultados del proyecto europeo PACHELBEL (Policy Addressing Climate Change and Learning about Consumer Behaviour and Everyday Life), financiado por la Comisión Europea (EU-FP7, Grant Agreement 244024). Además, se ha beneficiado de las discusiones y las aportaciones del profesor Tom Horlick-Jones, codirector del proyecto PACHELBEL e inestimable fuente de inspiración para todas las personas que hemos compartido sus proyectos de investigación en los últimos años. Desafortunadamente, el profesor Tom Horlick-Jones falleció mientras este artículo se encontraba en una fase avanzada de redacción. 


\section{Referencias bibliográficas}

Alaszewski, A. y Horlick-Jones, T. (2003). «How can doctors communicate information about risk more effectively?». British Medical Journal, 327, 728-731. <http://dx.doi.org/10.1136/bmj.327.7417.728>.

BarnetT, J. (2008). «Making sense of information provision». Ponencia presentada en el First ISA Forum [en línea]. Barcelona, 7 de septiembre.

Beck, U. (1992). Risk Society: Towards a New Modernity. Londres: Sage.

Bostrom, A.; Fischhoff, B. y Morgan, M.G. (1992). «Characterizing mental models of hazardous processes: A methodology and an application to radon». Journal of Social Issues [en línea], 48 (4), 85-100. <http://dx.doi.org/10.1111/j.1540-4560.1992.tb01946.x>.

Brundtland, G.H. (1989). Nuestro futuro común. Madrid: Alianza.

Buley, P. (1996). Risk communication by government departments. Londres: Report to the Health \& Safety Executive.

Covello, V.T. (1985). «Social and behavioral research on risk: Uses in risk management decision making». En: Environmental Impact Assessment, Technology Assessment, and Risk Analysis [en línea]. Berlín, Heidelberg: Springer Verlag, 1-14. <http://dx.doi.org/10.1007/978-3-642-70634-9_1>.

DAKE, K. (1991). «Orienting dispositions in the perception of risk an analysis of contemporary worldviews and cultural biases». Journal of Cross-cultural Psychology [en línea], 22 (1), 61-82. <http://dx.doi.org/10.1177/0022022191221006>.

Dobson, A. (1997). Pensamiento politico verde. Barcelona: Paidós.

Douglas, M. (1996). La aceptabilidad del riesgo según las ciencias sociales. Barcelona: Paidós.

Douglas, M. y Wildavsky, A. (1982). Risk and Culture. Berkeley, Los Angeles, Londres: University of California Press.

Espluga, J. (2004a). "Conflictes socioambientals i estudi de la percepció social del risc». Papers: Revista de Sociologia, 72, 145-162.

- (2004b). «La exposición laboral a pesticidas en la agricultura: Un caso de aparente subestimación del riesgo». Sociología del Trabajo, 51, 33-60.

- (2005). «Precautionary Local Politics and Coping with Risks of Radiofrequency Fields in Spain». International Journal of Global Environment Issues [en línea], 5 (1-2), 68-76. <http://dx.doi.org/10.1504/ijgenvi.2005.006263>.

- (2006). «Siniestralidad laboral y sociedad del riesgo: Paradojas de un desencuentro». Sociología del Trabajo, 58, 137-158.

Espluga, J.; Farré, J.; Gonzalo, J.; Horlick-Jones, T.; Prades, A.; Oltra, J. y Navajas, J. (2009). "Do the people exposed to a technological risk always want more information about it?: Some observations on cases of rejection». En: MARtorell, S.; Guedes, C. y Barnett, J. (eds.). Safety, Reliability and Risk Analysis. Londres: CRC Press. Taylor \& Francis, 1301-1308.

Espluga, J.; Farré, J.; Gonzalo, J. y Prades, A. (2014). «Factores que inhiben la movilización social: El caso del área petroquímica de Tarragona». Revista Española de Investigaciones Sociológicas [en línea], 146, 191-216. <http://dx.doi.org/10.5477/cis/reis.146.191>.

Espluga, J.; Prades, A. y Gonzalo, J. (2010). «Communicating at the edge: Risk communication processes and structural conflicts in highly industrialized petrochemical areas». Catalan Journal of Communication and Cultural Studies [en línea], 2 (2), 231-251. $<$ http://dx.doi.org/10.1386/cjcs.2.2.231_1>. 
EEA (European Environment Agency) (2013). Late Lessons from Early Warnings: Science, Precaution and Innovation. Luxemburgo: Publications Office of the European Union.

Fischhoff, B. (1995) «Risk Perception and Communication Unplugged: Twenty Years of Process». Risk Analysis, 15 (2), 137-145. <http://dx.doi.org/10.1111/j.1539-6924.1995.tb00308.x>.

Fischhoff, B.; Slovic, P.; Lichtenstein, S.; Read, S. y Combs, B. (1978). «How safe is safe enough?: A psychometric study of attitudes towards technological risks and benefits». Policy Sciences [en línea], 9 (2), 127-152.

<http://dx.doi.org/10.1007/bf00143739>.

Fischhoff, B.; Slovic, P.; Lichtenstein, S. (1981) «Lay Foibles and Expert Fables in Judgements about Risk». En: T. O’Riordan y R.K. Turner (eds.). Progress in Resource Management and Environmental Planning, vol. 3. Chichester: Wiley.

Fitchen, J.; Heath, J. y Fessenden-Raden, J. (1987). "Risk perception in community context: A case study». En: Johnson, B. y Covello, V. (eds.). The social and cultural construction of risk [en línea]. Dordrecht: Reidel, 31-54. <http://dx.doi.org/10.1007/978-94-009-3395-8_2>.

FlynN, J.; Slovic, P. y Mertz, C.K. (1993). «Decidedly different: Expert and public views of risks from a radioactive waste repository». Risk Analysis [en línea], 13 (6), 643-648. <http://dx.doi.org/10.1111/j.1539-6924.1993.tb01326.x>.

Funtowicz, S. y Ravetz, J.R. (1990). Uncertainty and Quality in Science for Policy [en línea]. Dordrecht: Kluwer. <http://dx.doi.org/10.1017/s0012217300011513>.

Giddens, A. (1984). The constitution of society: Outline of the theory of structuration. Oxford: Polity Press.

Gonzalo Iglesia, J. y Farré Coma, J. (2011). Teoría de la Comunicación de Riesgo. Barcelona: UOC.

Hertel, R.F. y Henseler, G. (eds.) (2007). EriK: Development of a multi-stage risk communication process. Berlín: Bundesinstitut für Risikobewertung.

Horlick-Jones, T. (2005). «Informal logics of risk: Contingency and modes of practical reasoning». Journal of Risk Research [en línea], 8 (3), 253-272. <http://dx.doi.org/10.1080/1366987042000270735>.

- (2008). «Communities of risk research and risk practice: Divided by a common language?». Journal of Risk Research [en línea], 11 (1-2), 169-174. <http://dx.doi.org/10.1080/13669870701875719>.

Horlick-Jones, T. y Prades, A. (2009). «On interpretative risk perception research: Some reflections on its origins; its nature; and its possible applications in risk communication practice». Health, Risk \& Society [en línea], 11 (5), octubre, 409-430. <http://dx.doi.org/10.1080/13698570903180448>.

- (2014). «Translating between social worlds of policy and everyday life: The development of a group-based method to support policy-making by exploring behavioural aspects of sustainable consumption». Public Understanding of Science [en línea]. <http://dx.doi.org/10.1177/0963662514525556>.

Horlick-Jones, Tom y RosenHEAD, Jonathan (2002). «Investigating risk, organisations and decision support through action research». Risk Management, 4 (4), 45-63. <http://dx.doi.org/10.1057/palgrave.rm.8240132>.

- (2007). "The uses of observation: Combining problem structuring methods and ethnography». Journal of Operational Research Society [en línea], 58, 588-601. <http://dx.doi.org/10.1057/palgrave.jors.2602271>. 
- (2013). «Ambiguity and therapy in risk management». EURO Journal on Decision Processes 1 (3-4) , 263-283. <http://dx.doi.org/10.1007/s40070-013-0012-7>.

Horlick-Jones, T.; Sime, J. y Pidgeon, N. (2003). «The social dynamics of environmental risk perception: Implications for risk communication research and practice». En: Pidgeon, N.; Kasperson, R. y Slovic, P. (eds.). The social amplification of risk [en línea], 262-285. <http://dx.doi.org/10.1017/cbo9780511550461.012>.

Horlick-Jones, T.; Walls, J.; Rowe, G.; Pidgeon, N.; Poortinga, W.; Murdock, G. y O'Riordan, T. (2007). The GM debate: Risk, politics and public engagement. Londres: Routledge.

Irwin, A.; Simmons, P. y Walker, G. (1999). «Faulty environments and risk reasoning: The local understanding of industrial hazards. Environment and Planning A [en línea], 31 (7), 1311-1326. <http://dx.doi.org/10.1068/a311311>.

Irwin, A. y Wynne, B. (eds.) (1996). Misunderstanding science?: The public reconstruction of science and technology. Cambridge: Cambridge University Press.

Kasperson, R.E. (1992). "The Social Amplification of Risk: Progress in Developing an Integrative Framework». En: S. KRIMsky y D. Golding (eds.). Social Theories of Risk. Wesport, Londres: Praeger.

Kasperson, R.E.; Renn, O.; Slovic, P.; Brown, H.S.; Emel, J.; Goble, R.; Kasperson, J.X.; Ratick, S. (1988) «The Social Amplification of Risk: A Conceptual Framework». Risk Analysis, 8 (2), 177-187. <http://dx.doi.org/10.1111/j.1539-6924.1988.tb01168.x>.

Krimsky, S. y Golding, D. (eds.) (1992). Social Theories of Risk. Londres: Praeger.

Layard, R. y Glaister, S. (1994). Cost-benefit Analysis. Cambridge (UK): Cambridge University Press.

LeIss, W. (1996). "Three phases in the evolution of risk communication practice». The Annals of the American Academy of Political and Social Science [en línea], 85-94. <http://dx.doi.org/10.1177/0002716296545001009>.

Leмкоw, L. (1984). La protesta antinuclear. Madrid: Mezquita.

- (2002), Sociología ambiental. Barcelona: Icària.

Macgill, S. (1987). The politics of anxiety. Londres: Pion.

MARRIS, C.; LANGFORD, I. y O'RIORDAN, T. (1996). Integrating sociological and psychological approaches to public perceptions of environmental risk: Detailed results from a questionnaire survey: CSERGE Working Paper GEC 96-07. Norwich: University of East Anglia.

- (1998). «A quantitative test of the cultural theory of risk perceptions: Comparisons with the psychometric paradigm». Risk Analysis [en línea], 18 (5), 635-648. <http://dx.doi.org/10.1111/j.1539-6924.1998.tb00376.x>.

MejlgaARd, N. (2009). "The trajectory of scientific citizenship in Denmark: Changing balances between public competence and public participation». Science and Public Policy [en línea], 36 (6), 483-496.

<http://dx.doi.org/10.3152/030234209x460962>.

Моцотсн, H. (2008). "Thinking like a state meets thinking like a person: Some local variations». Ponencia presentada en el International Sociological Association Congress. Barcelona, 7 de septiembre.

Oтway, H. (1992). «Public wisdom, expert fallibility: Toward a contextual theory of risk». En: Krimsky, S. y Golding, D. (eds.). Social theories of risk. Westport, CT: Praeger, 215-228. 
Otway, H. y Cohen, J.J. (1975). «Revealed Preferences: Comments on the Starr Benefit-Risk Relationships». International Institute for Applied Systems Analysis Research Memorandum, 75-80.

Pidgeon, N.; Kasperson, R. y Slovic, P. (eds.) (2003). The Social Amplification of Risk. Cambridge: Cambridge University Press.

Petts, J.; Horlick-Jones, T.; Murdock, G.; Hargreaves, D.; Mclachlan, S. y Lofstedt, R. (2001). Social amplification of risk: The media and the public. Sudbury: HSE Books.

Poumadère, M. (2008). «Public information and risk prevention after the AZF accident (France, September 2001)». Comunicación presentada en el First ISA Forum on Sociology: "Sociology and public debate». Barcelona, del 5 al 9 de septiembre. TG04 Sociology of Risk and Uncertainty.

Prades, A.; Holick-Jones, T.; Barnett, J.; Constantin, M.; Enander, A.; EspluGa, J.; Konrad, W.; Poumadère, M. y Rosenhead, J. (2015). «PACHELBEL/ STAVE: Shining a light on citizens' everyday environment-related behaviours». En: Martinuzzi, A. y Sedlacko, M. (eds.). Knowledge Brokerage for a Sustainable Europe: Innovative tools for enhancing the connectivity of research and policy making on sustainable development issues. Sheffield (UK): Greenleaf.

Prades, A. y SolÀ, R. (2004). "De la percepción a la gobernanza del riesgo: Evolución de la línea de investigación». Nuclear España, 244, 29-34.

Prades lópez, A. y González Reyes, F. (1999). "La percepción social del riesgo: Algo más que discrepancia expertos/público». Nucleus, 26.

Prades lópez, A.; Horlick-Jones, T.; Oltra, C. y Solá, R. (2008). «Lay perceptions of nuclear fusion: Multiple modes of understanding». Science and Public Policy [en línea], 35 (2), 95-105.

<http://dx.doi.org/10.3152/030234208x282853>.

Puy, A. (1995). Percepción social de los riesgos. Madrid: Mapfre.

Renn, O. (1991). "Risk Communication and the Social Amplification of Risk». En: Kasperson, R.E. y Stallen, P.J.M. Communicating Risks to the Public: International Perspectives [en línea]. Dordrecht: Kluwer Academic Publishers, 287-324. <http://dx.doi.org/10.1007/978-94-009-1952-5_14>.

- (1992). «Concepts of risc: A Classification». En: Krimsky, S. y Golding, D. (eds.). Social Theories of Risk. Westport y Londres: Praeger, 53-81.

- (2003). "Social amplification of risk in participation: two case studies». En: Pidgeon, N.; Kasperson, R. y Slovic, P. (eds.). The Social Amplification of Risk [en línea]. Cambridge: Cambridge University Press, 374-400. <http://dx.doi. org/10.1017/cbo9780511550461.017>.

- (2006). «Participatory processes for designing environmental policies». Land Use Policy [en línea], 23, 34-43.

$<$ http://dx.doi.org/10.1016/j.landusepol.2004.08.005>.

- (2008). Risk governance: Coping with uncertainty in a complex world [en línea]. Londres: Earthscan. <http://dx.doi.org/10.1007/s11069-008-9286-7>.

Riechmann, J.; González-Reyes, L.; Herrero, Y. y Madorrán, C. (2012). Qué hacemos hoy cuando nos encontramos frente a la amenaza de una crisis mayor que la econòmica: la ecològica. Madrid: Akal.

Ryle, G. (1971). "The thinking of thoughts: what is "Le Penseur" doing? Collected Papers, 2. Londres: Hutchinson, 480-496. 
Sjöвerg, L. (1998). «Worry and risk perception». Risk Analysis [en línea], 18 (1), 85-93. <http://dx.doi.org/10.1111/j.1539-6924.1998.tb00918.x>.

Sjöberg, L.; Moen, B.E. y Rundmo, T. (2004). Explaining risk perception: An evaluation of the psychometric paradigm in risk perception research. Trondheim: The Norwegian Research Council's RISIT.

Slovic, P. (1993). «Perceived risk, trust, and democracy». Risk Analysis, 13 (6), 675682.

- (1996). «Perception of risk from radiation». Radiation Protection Dosimetry [en línea], 68 (3-4), 165-180.

<http://dx.doi.org/10.1093/oxfordjournals.rpd.a031860>.

- (2000). The perception of risk. Londres: Earthscan.

Slovic, P. y Peters, E. (1998). «The importance of worldviews in risk perception». Risk Decisión and Policy, 3 (2), 165-170. <http://dx.doi.org/10.1080/135753098348275>.

Starr, C. (1969). «Social Benefit versus Technological Risck». Science, 165, $1232-$ 1238.

Turner, G. y Wynne, B. (1992). «Risk communication: A literature review and some implications for biotechnology». En: Durant, J. (ed.). Biotechnology in Public: A Review of Recent Research. Londres: Science Museum for the European Federation of Biotechnology, 109-141.

Walker, G.; Simmons, P.; Wynne, B. e Irwin, A. (1998). Public perception of risks associated with major accident hazards. Sudbury: HSE Books.

Walls, J.; Pidgeon, N.; Weyman, A. y Horlick-Jones, T. (2004). "Critical trust: Understanding lay perceptions of health and safety risk regulation». Health, Risk \& Society [en línea], 6, 133-150. <http://dx.doi.org/10.1080/1369857042000219788>.

Wardman, J.K. (2008). "The Constitution of Risk Communication in Advanced Liberal Societies». Risk Analysis [en línea], 28 (6), 1619-1637. <http://dx.doi.org/10.1111/j.1539-6924.2008.01108.x>.

Wildavsky, A. y DaKe, K. (1990). "Theories of risk perception: Who fears what and why?». Daedalus, 41-60.

Wright, D. (ed.) (2006). "STAkeholders in Risk Communication (STARC)». PSCEurope/RD/011, Draft Final Report. Bruselas: Public Safety Communication Europe.

Wynne, B. (1980). «Technology, Risk and Participation: on the Social Treatment of Uncertainty». En: J. ConRad (ed.). Society, Technology and Risk. London, New York: Academic Press, 87-103.

- (1982). Rationality and Ritual: The Windscale Inquiry and Nuclear Decisions in Britain. Chalfont St. Gilles: British Society for the History of Science.

- (1992). «Risk and Social Learning: Reification to Engagement». En: KRIMSKY, S. y Golding, D. (eds.). Social Theories of Risk. Westport, Londres: Praeger, 275-299.

- (1996). «May the Sheep Safely Graze?: A Reflexive View of the Expert-Lay Knowledge Divide». En: Lash, S.; Szerszynski, B. y Wynne, B. Risk, Environment and Modernity [en línea]. Londres: Sage, 44-83. <http://dx.doi.org/10.4135/9781446221983.n3>.

Zonabend, F. (1993). The nuclear peninsula [en línea]. Cambridge: Cambridge University Press y París: Éditions de la Maison des Sciences de l'Homme. <http:// dx.doi.org/10.1163/182539189x00275>. 